
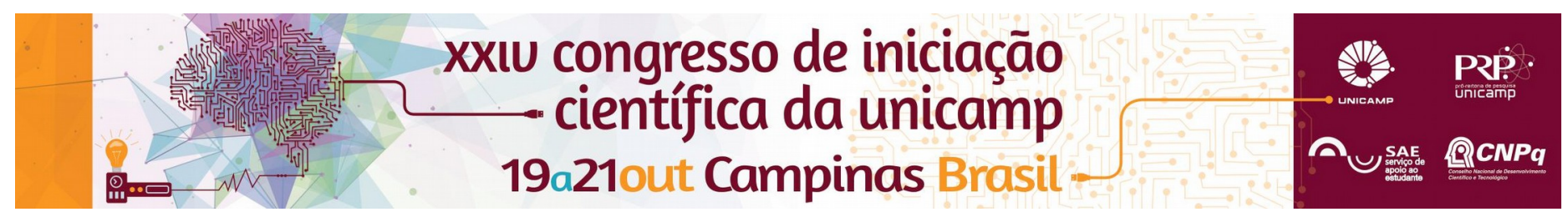

\title{
Avaliação da eficiência de uma wetland construída na remoção de matéria orgânica e nitrogênio no pós tratamento de efluentes domésticos.
}

\author{
Junia T. Martins*, Marta G. S. Pires.
}

\section{Resumo}

Buscou-se avaliar a eficiência de uma wetland construída de fluxo horizontal sub superficial utilizando duas macrófitas separadamente e variando o Tempo de Detenção Hidráulica (TDH). Verificou-se que a wetland apresentou melhores resultados quando plantada com a macrófita Cana $x$ Generalis e que o maior percentual de poluentes foi removido no menor TDH aplicado.

\section{Palavras-chave:}

Wetland, Efluente Doméstico, Nitrogênio.

\section{Introdução}

Wetlands construídas (WC's) são sistemas de tratamento de efluentes caracterizadas por leitos artificiais, preenchidos com plantas aquáticas (macrófitas) em substratos (solo, calhas, pneus, entre outros). Elas apresentam baixo custo de implantação, operação simples, estética agradável e versatilidade na remoção de poluentes ${ }^{1}$. Desta forma, este projeto buscou avaliar a eficiência de uma wetland construída de fluxo horizontal sub superficial no pós tratamento de efluentes domésticos.

\section{Resultados e Discussão}

A wetland em questão é uma caixa com dimensões $66 \times 33 \times 34 \mathrm{~cm}$ (comprimento, largura, altura), preenchida com fragmentos de telha cerâmica. Em uma primeira etapa a WC foi plantada com a macrófita Mini Papiro (Cyperus Isocladus) operando com Tempo de Detenção Hidráulica (TDH) de 17h e 48h e em uma segunda etapa a macrófita usada foi a Biri (Canna $x$ Generalis), com TDH de 2, 5 e 7 dias.

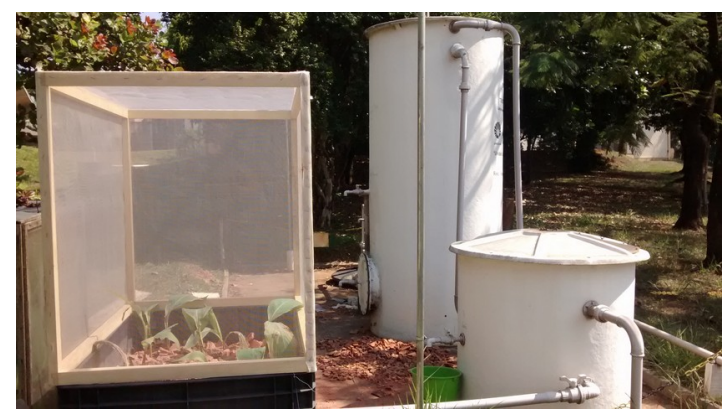

Figura 1. Wetland construída

Os parâmetros físico-químicos analisados neste projeto foram $\mathrm{pH}$, temperatura, condutividade elétrica (C.E),

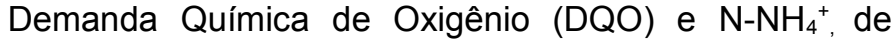
acordo com Standard Methos of Examination of Water and WasteWater.

$\mathrm{Em}$ todas as amostras $\mathrm{o} \mathrm{pH}$ permaneceu próximo ao neutro e a temperatura variou de $17-28^{\circ} \mathrm{C}$ de acordo com o clima do dia da coleta.
Tabela 1. Média de remoção de DQO, $\mathrm{N}_{-} \mathrm{NH}_{4}{ }^{+} \mathrm{e}$ Condutividade Elétrica (C.E)

\begin{tabular}{cc|ccc}
\hline & & \multicolumn{3}{|c}{ Média de Remoção (\%) } \\
& TDH (dias) & DQO & N-NH4+ & C.E. \\
\hline \multirow{2}{*}{ C. Isocladus } & 0.7 & 48.1 & 8.0 & 3.7 \\
& 2 & 37.9 & 14.9 & 6.2 \\
\hline \multirow{2}{*}{ Canna x } & 2 & 47.0 & 54.4 & 36.5 \\
Generalis & 5 & 55.7 & 58.3 & 41.3 \\
& 7 & 59.6 & 58.6 & 46.3
\end{tabular}

Na primeira etapa, não houve expressiva remoção de C.E e N-NH${ }_{4}^{+}$, este último evidenciando a falta de oxigênio dissolvido no leito, o que impede a completa

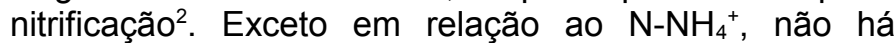
evidência estatística de que há diferença significativa de eficiência entre os TDH's de $17 \mathrm{~h}$ e $48 \mathrm{~h}$, segundo o teste ANOVA, com margem de segurança de 95\%. Já na segunda etapa, a wetland apresentou melhores eficiências de remoção em relação a quando estava plantada com a Mini Papiro. Assim como na primeira etapa, também não é possível verificar diferença estatisticamente significativa entre os três TDH's aplicados, fazendo com que cerca de $80 \%$ da remoção que ocorreu, ou mais, tenha se dado no menor TDH aplicado.

\section{Conclusão}

A wetland apresentou maior eficiência de remoção dos poluentes quando plantada com a macrófita Cana $x$ Generalis. Tanto no tratamento utilizando a Mini Papiro, quanto no tratamento utilizando a Biri, a maior parcela de remoção dos poluentes ocorreu no menor TDH.

\section{Agradecimentos}

Agradeço ao CNPQ pela concessão da bolsa de Iniciação Cientifica.

\footnotetext{
${ }^{1}$ Almeida, R. A. Eficiência de espécies vegetais na purificação de esgoto sanitário. Pesq Agropeq Trop, vol 1, n. 37, p. 1-9, 2007.

${ }^{2}$ Vymazal, J. Constructed Wetlands for Wastewater Treatment. Water , v. 2, n. 3, p. $530-549,2010$.
} 